\title{
Cultural Landscape: Brand Knowledge Wisatawan tentang Bali dalam Online Travel Review Communication Platform
}

\author{
Ni Luh Ramaswati Purnawan', I Gede Pitana², I Nyoman Darma Putra ${ }^{3}$ \\ ${ }^{1}$ Fakultas Ilmu Sosial dan Ilmu Politik, Universitas Udayana, Denpasar, 80114, Indonesia \\ ${ }^{2}$ Fakultas Pertanian, Universitas Udayana, Denpasar, 80114, Indonesia \\ ${ }^{3}$ Fakultas Ilmu Budaya, Universitas Udayana, Denpasar, 80114, Indonesia
}

ramaswati.purnawan@unud.ac.id

Kebudayaan Bali memiliki peran penting bagi citra dan competitiveness Bali dalam industri pariwisata global dan unsur-unsur budaya telah digunakan sebagai ikon pemasaran pariwisata. Namun demikian, dalam perjalanan kepariwisataan di Bali, motivasi wisatawan berkunjung beragam karena banyaknya alternatif aktivitas wisata ditawarkan di Bali. Di sisi lain, perkembangan teknologi komunikasi merubah trend wisatawan mempersiapkan perjalanan wisata melalui pencarian informasi dengan merujuk ke rekomendasi dari sosial media secara online, salah satu yang populer adalah travel review forum. Tulisan ini bertujuan untuk mengetahui brand knowledge wisatawan tentang Bali melalui mediasi online travel review platform. Penelitian ini merupakan penelitian kuantitatif. Pengumpulan data dilakukan melalui survey dengan kuesioner online sebagai instrument penelitian. Analisis data dilakukan menggunakan metode Spearman Rank Correlation. Hasil penelitian menunjukkan bahwa eWOM, khususnya online travel review memiliki hubungan yang kuat dan positif terhadap brand knowledge wisatawan bahwa Bali merupakan destinasi wisata alam. Sebaliknya, hubungan yang lemah dan negatif terjadi antara eWOM terhadap brand knowledge wisatawan tentang Bali sebagai destinasi wisata budaya.

Kata kunci: komunikasi pemasaran, brand knowledge, eWOM, online travel review, cultural landscape

\section{Cultural Landscape: Travellers'Brand Knowledge toward Bali in Online Travel Review Communication Platform}

Balinese culture has an important role for the image and competitiveness of Bali in the global tourism industry, and cultural elements have long been used as icons of tourism marketing. However, motivation of tourists to visit varies due to many alternative activities offered in Bali. This paper aimed to determine traveller's brand knowledge toward Bali through online travel review platform. This is a quantitative research. Data was collected through a survey with online questionnaire as a research instrument. Data analysis was performed using Spearman Rank Correlation method. Result showed that eWOM especially online travel reviews, has a strong and positive relationship with tourists' brand knowledge that Bali is a natural tourist destination. This means that the more information available through online travel reviews can increase traveller brand knowledge that Bali is a natural tourist destination. On the other hand, the information does not increase tourists brand knowledge about Bali as cultural tourism destination.

Keywords: marketing communication, brand knowledge, eWOM, online travel review, cultural landscape

Proses Review : 1 - 20 Mei 2021, Dinyatakan Lolos: 31 Mei 2021 


\section{PENDAHULUAN}

Bali telah berkomitmen untuk mengembangkan pariwisata berbasis budaya. sebagaimana ditetapkan dalam Peraturan Daerah No.2 Tahun 2012 tentang Kepariwisataan Budaya Bali. Kebudayaan telah lama berkontribusi untuk menarik minat wisatawan mancanegara berkunjung ke Bali. Hal ini telah dimulai sejak Bali menjadi bagian dari pemerintahan kolonial Belanda tahun 1908. Salah satu kebijakan yang diambil oleh Pemerintahan Belanda saat itu adalah Balinization of Bali (Balisering), yakni menjaga budaya Bali tetap hidup dan berkembang autentik dalam masyarakat, dan menjadikan Bali sebagai "living museum" (Picard, 1995). Pemerintahan Belanda menyadari bahwa warisan budaya Bali penting untuk dijaga, selain untuk pelestarian budaya, sekaligus dapat menjadi aset utama untuk menarik minat orang luar datang ke Bali untuk melihat autentitas budaya dan kehidupan masyarakat ditengah modernisasi pada saat itu.

Setelah dibukanya jalur transportasi dan kedatangan orang asing ke Bali, nama Bali semakin dikenal dengan artistic dan ceremonial manifestation sebagai image budaya Bali. Hal ini terlihat dari buku dan laporan ilmiah tentang Bali yang ditulis wisatawan yang datang membentuk citra tentang pesona Pulau Bali dan kekayaan budayanya sebagai sebuah taman surga (paradise), tamannya para dewa (Pulau Dewata) (Swandi, 2017). Penggunaan unsur budaya sebagai ikon pemasaran pariwisata Bali terus berlanjut hingga saat ini. Bahkan brand terbaru yakni Bali dengan tagline "The Island of Gods" yang diperkenalkan mulai awal tahun 2017 memasukkan unsur budaya seperti pura, berdampingan dengan gambar pulau Bali dan bunga khas tradisional Bali, yakni pucuk rejuna. Hal ini menunjukkan bahwa kebudayaan Bali memiliki peran penting bagi citra dan competitiveness Bali dalam industri pariwisata global dan unsur-unsur budaya telah digunakan sebagai ikon pemasaran pariwisata. Citra Bali terletak pada kekuatan adat istiadat tradisi budaya dan agamanya (Malik, 2016).

Namun demikian, dalam perjalanan kepariwisataan di Bali, motivasi wisatawan berkunjung beragam karena adanya beberapa alternatif aktivitas wisata yang dapat dilakukan. Kementerian Pariwisata telah melakukan pengelompokkan pilihan aktivitas wisata yang dapat dilakukan di Indonesia, yang dibedakan menjadi lima keajaiban (5 wonders), yakni wisata alam (nature, scenic landscape \& wildlife), wisata kuliner dan kebugaran (culinary \& wellness), wisata budaya (arts, culture \& heritage), rekreasi dan kesenangan (recreation \& leisure), wisata petualangan (adventures) (Indonesia Travel, 2019).

Selain beragamnya pilihan aktivitas wisata, perkembangan teknologi informasi dan komunikasi juga berpengaruh bagi sektor pariwisata. Teknologi telah merubah pengalaman berwisata dimulai saat perencanaan, pencarian informasi,

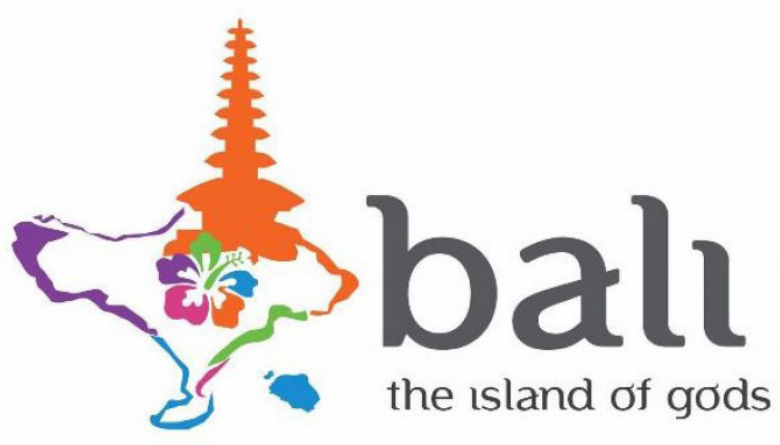

Gambar 1. Logo dan brand Bali

tahap berwisata hingga setelah melakukan kunjungan wisata. Hasil penelitian Travel Industry Association tahun 2005 menyatakan bahwa perkembangan teknologi mendorong meningkatnya pemanfaatan internet oleh calon wisatawan untuk merencanakan perjalanan wisata Hal ini menyebabkan pencarian informasi yang berkaitan dengan perjalanan wisata merupakan salah satu aktivitas online yang populer diantara pengguna internet (Pew Internet \& American Life Project, 2006; dalam Gretzel dkk, 2007). Tren ini telah diadopsi oleh Kementerian Pariwisata. Salah satu upaya pemerintah untuk menarik wisatawan nusantara maupun wisatawan asing dengan meningkatkan destinasi digital, yakni dengan memanfaatkan internet dan membentuk komunitas berjiwa muda untuk mempromosikan pariwisata melalui media sosial (Anom dan Revias, 2019).

Urgensi tulisan ini terletak pada pertimbangan bahwa kehidupan saat ini telah menjadi semakin digital. Kemajuan teknologi informasi dan komunikasi telah merubah cara wisatawan untuk membeli dan mengkonsumsi produk/ jasa wisata (Munar, 2012). Perubahan tersebut ditandai dengan berkembangnya user-generated content (konten yang dibuat oleh pengguna internet/sosial media). Jika sebelumnya organisasi penyedia barang/jasa memegang 'kendali' dengan konten informasi yang diberikan kepada konsumen mereka, namun dalam media baru ini, trend menunjukkan bahwa konsumenlah yang memegang control atas konten informasi yang disebarluaskan. Hal ini menyebabkan electronic word-of-mouth atau eWOM, seperti online comunities dan travel reviews menjadi salah satu rujukan penting sebelum calon wisatawan memutuskan untuk melakukan perjalanan wisata ke suatu destinasi, sehingga eWOM dikatakan sebagai salah satu medium promosi yang efektif dalam mempengaruhi potensial konsumen. Namun demikian, hasil penelitian berbasis content analysis oleh Purnawan, Pitana dan Darma Putra (2019) menunjukkan bahwa pembicaraan tentang Bali secara online dalam sosial media, khususnya travel review forum seperti TripAdvisor, lebih banyak didominasi kata-kata yang berkaitan dengan pilihan aktivitas alam dan adventure, dibandingkan kata-kata tentang aktivitas budaya. Jika mengacu pada konsepsi Keller (1993) bahwa brand knowledge, yang terdiri 
dari brand awareness dan brand image merupakan hal mendasar bagi wisatawan untuk memilih, mengevaluasi dan mengambil keputusan berwisata, maka hasil penelitian tersebut dapat menunjukkan adanya gap antara identitas Bali sebagai destinasi wisata budaya dengan perceived brand knowledge yang dimiliki oleh wisatawan berdasarkan informasi yang diperoleh dalam platform online.

Berdasarkan pada penelitian tersebut, maka tulisan ini bertujuan untuk mengetahui secara empiris brand knowledge wisatawan tentang Bali terutama bagi wisatawan yang termediasi internet/media sosial, khususnya online travel review. Penelitian ini dapat memberikan perspektif baru bagi kepariwisataan Bali berkaitan dengan perkembangan teknologi dan dampaknya bagi perilaku wisatawan, termasuk pencarian informasi dan pilihan aktivitas yang dilakukan wisatawan di Bali. Jika selama beberapa dekade, Bali digambarkan sebagai destinasi wisata budaya, di mana aktivitas yang berkaitan dengan menikmati hasil/produk budaya dan lifestyle/kehidupan masyarakat Bali menjadi prioritas (soundscapes dan landscapes); maka penelitian ini dapat menunjukkan bagaimana brand knowledge wisatawan yang termediasi online travel review platform serta apakah brand knowledge tersebut menimbulkan ada/tidaknya trend pergeseran preference aktivitas wisatawan di Bali.

\section{METODE PENELITIAN}

Penelitian ini merupakan penelitian kuantitatif. Pengumpulan data dilakukan melalui survey dengan kuesioner online sebagai instrument penelitian. Data primer dalam penelitian ini diperoleh melalui sampel penelitian berjumlah 273 orang, diperoleh dengan metode convenience sampling. Analisis data dilakukan menggunakan metode Spearman Rank Correlation. Korelasi merupakan angka yang menunjukkan arah dan kuatnya hubungan variabel eWOM dan brand knowledge wisatawan tentang Bali. Arah hubungan dapat dinyatakan dalam bentuk hubungan positif atau negatif. Sementara, kuatnya hubungan dapat dilihat dari besarnya koefisien korelasi.

Ruang lingkup penelitian ini adalah komunikasi pemasaran dan perilaku konsumen. Komunikasi pemasaran (marketing communication) mengacu kepada aktivitas yang digunakan oleh organisasi penyedia barang atau jasa untuk menjangkau target audience melalui berbagai medium komunikasi dan menghasilkan adanya dialog. Dalam konsepsi komunikasi pemasaran, terdapat tiga dimensi penting, yakni adanya keterlibatan (engagement), target audience dan response (Fill dan Turnbull, 2009).

Komunikasi pemasaran digunakan untuk menjangkau beragam target audience dan hendaknya merupakan aktivitas yang berorientasi pada target audience (audience- centre activity) sehingga pesan yang disampaikan merupakan bentuk perhatian penyedia produk/jasa terhadap kebutuhan target audience. Luaran dari aktivitas komunikasi pemasaran yang dilakukan diharapkan akan mendorong adanya response dari target audience. Respon dapat dibedakan menjadi tiga (3), yakni adanya perubahan sikap (attitudinal), adanya keterikatan emosional konsumen terhadap brand (emotional), dan adanya perubahan perilaku (behavioral). Respon ini sekaligus dapat digunakan untuk mengukur kesuksesan program komunikasi pemasaran yang telah dilakukan.

Beberapa platforms komunikasi yang biasa dilakukan dalam kegiatan pemasaran termasuk diantaranya iklan (advertising), promosi (sales promotions), events, kehumasan dan publisitas (public relations), pemasaran langsung dan interaktif (direct and interactive marketing), personal selling dan word-of-mouth marketing (Kotler dan Keller, 2012). Penelitian ini secara khusus terfokus pada pemanfaatan word-of-mouth marketing, yang dalam tulisan ini selanjutnya disebut $e W O M$.

Istilah eWOM pertama kali diperkenalkan oleh HennigThurau, Qwinner, Walsh dan Grumbler (2004), yang menyatakan bahwa eWOM adalah pernyataan dari mereka yang telah mengkonsumsi produk/jasa, baik pernyataan positif maupun negatif, yang disampaikan kepada berbagai individu dan/atau organisasi melalui internet. Definisi tersebut mengandung dimensi $e W O M$ yang terdiri dari adanya pesan, komunikator dan penerima pesan (Mizani, 2015). Bentuk eWOM dapat berupa rating atau review. Review yang diberikan dapat berupa informasi maupun rekomendasi, baik yang bersifat positif maupun negatif (Park dkk., 2007).

Berdasarkan hal di atas, komunikasi pemasaran mempunyai peran vital dalam menciptakan brand yang kuat dan memiliki keunggulan kompetitif bagi suatu destinasi. Sebuah brand tidak hanya sekedar symbol atau logo semata yang membedakannya dengan destinasi lainnya, namun lebih merupakan penanda yang dapat merepresentasikan diri, reputasi dan nilai-nilai dasar yang dianut. Untuk memastikan efektivitas program, komunikasi pemasaran yang dilakukan berdasar pada tingkah laku, kebutuhan informasi dan gaya hidup target audience. To be successful, marketing communication should be grounded in the behaviour and informationprocessing needs and style of the target audience (Fill \& Turnbull, 2009)

Berkaitan dengan hal tersebut, memahami brand knowledge target audience menjadi penting. Sebagaimana dinyatakan Keller (2001; dalam Risitono, 2006), bahwa dalam proses pengambilan keputusan berwisata, potensial wisatawan akan memilih dan mengevaluasi suatu destinasi menggunakan brand knowledge yang dimiliki. Brand knowledge ini terbentuk dari awareness dan image target 
audience akan suatu destinasi, sehingga dikatakan bahwa brand knowledge merupakan inti dari destination branding. Brand knowledge refers to brand awareness (whether, and when, consumers know the brand) and brand image (what are the associations that consumers have with the brand) (Keller, 1993).

Brand awareness dapat memberi gambaran kekuatan suatu brand yang dilihat dari kemampuan konsumen untuk mengidentifikasi brand tersebut dalam kondisi yang berbeda-beda. Brandawareness merupakanhal fundamental dalam proses pengambilan keputusan berwisata. Brand awareness mengawali proses pengambilan keputusan (Crompton, 1992; dalam Sirakaya \& Woodside, 2004). Sementara itu, brand image didefinisikan sebagai persepsi target audience terhadap suatu brand yang direfleksikan melalui asosiasi brand tersebut dalam benak/memory targat audience. Konstruksi dan pemeliharaan brand image merupakan prasyarat penting dalam mengelola suatu brand (Park dkk, 1986; dalam Zhang, 2015).

Selain itu, teori yang berkaitan dengan perilaku konsumen digunakan dalam tulisan ini. Salah satu teori yang sentral dalam membahas perilaku konsumen adalah Information Processing Theory. Teori ini menekankan bahwa konsumen dalam mengambil keputusan melalui lima (5) tahapan, yakni 1) problem recognition; 2) information search; 3) alternative evaluation and selection; 4) outlet selection dan 5) purchase.

\section{ANALISIS DAN INTERPRETASI DATA}

\section{Profil responden}

Data dalam penelitian ini diperoleh dari 273 responden. Berdasarkan jenis kelamin responden dibedakan menjadi $50,5 \%$ adalah laki-laki dan $49,4 \%$ adalah perempuan. Usia responden paling banyak berasal dari kelompok umur di bawah 35 tahun $(59,3)$, diikuti kelompok umur antara 35 - 64 tahun $(38,5 \%)$ dan lebih dari 65 tahun $(2,2 \%)$. Responden sebagian besar merupakan pelajar (40,7\%), karyawan $(29,7 \%)$, pimpinan/manager $(26,4 \%)$, pensiunan $(2,2 \%)$ dan ibu rumah tangga $(1,1)$ (Tabel 1$)$.

Tabel 1. Profil Responden

\begin{tabular}{lll}
\hline & Frekuensi & Persentase \\
\hline Gender & & \\
\hline Laki-Laki & 138 & 50,5 \\
Perempuan & 135 & 49,5 \\
\hline Umur & & \\
\hline
\end{tabular}

\begin{tabular}{lll}
\hline Lebih muda dari 35 tahun & 162 & 59,3 \\
35-64 tahun & 105 & 38,5 \\
65 tahun ke atas & 6 & 2,2 \\
\hline Pekerjaan & \\
\hline Mahasiswa (termasuk & 111 & 40,7 \\
pascasarjana) & 3 & 1,1 \\
Ibu Rumah Tangga & 81 & 29,7 \\
Karyawan & 72 & 26,4 \\
Manager/Pimpinan & 6 & 2,2 \\
Pensiunan & & \\
\hline
\end{tabular}

\section{Sumber Informasi}

Internet merupakan sumber informasi utama dalam pencarian informasi perencanaan perjalanan wisata. Data menunjukkan bahwa $87.9 \%$ menyatakan sangat setuju bahwa sumber informasi online dan sosial media merupakan yang paling nyaman dimanfaatkan karena memiliki kemudahan, kecepatan dan keberagaman informasi yang dapat diakses terkait destinasi yang ingin dikunjungi. Aktivitas pencarian informasi melalui internet yang dimaksud merupakan kategori "dilakukan setiap saat $^{\text {ee }}$ (everytime I plan a trip) sebanyak $76.9 \%$, dengan jumlah online review yang dibaca rata-rata sebanyak 7-9 review atau lebih.

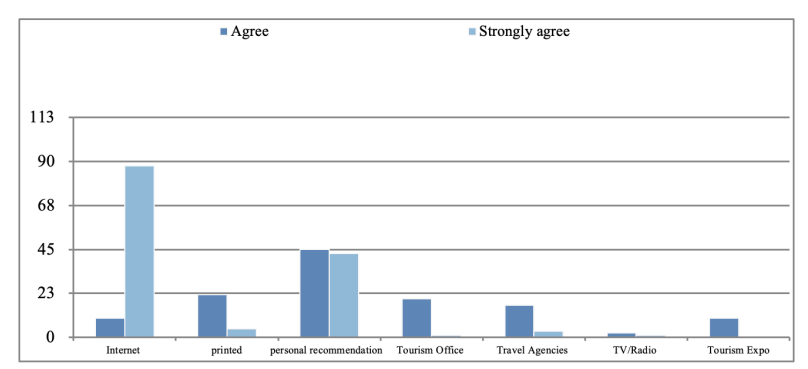

Gambar 2. Sumber Informasi

Brand Knowledge tentang Bali

Brand awareness responden tentang Bali termasuk baik. Hal ini ditunjukkan bahwa seluruh responden mengetahui tentang Bali, dengan kategori sangat sering (47.3\%) dan sering mendengar nama Bali $(52.7 \%)$. Brand image wisatawan tentang Bali dalam penelitian ini menunjukkan bahwa Bali dalam benak dan ingatan responden tergambarkan sebagai destinasi yang menawarkan wisata alam $(97,8 \%)$, adventure $(62,6 \%)$, budaya $(31,9)$, spa dan wellness $(20,9)$ serta lifestyle dan entertainment sebesar 5,5\%. (Gambar 3). Hal ini menunjukkan bahwa image tentang wisata budaya yang menjadi ciri khas kepariwisataan Bali berada di posisi ketiga setelah wisata alam dan adventure. 


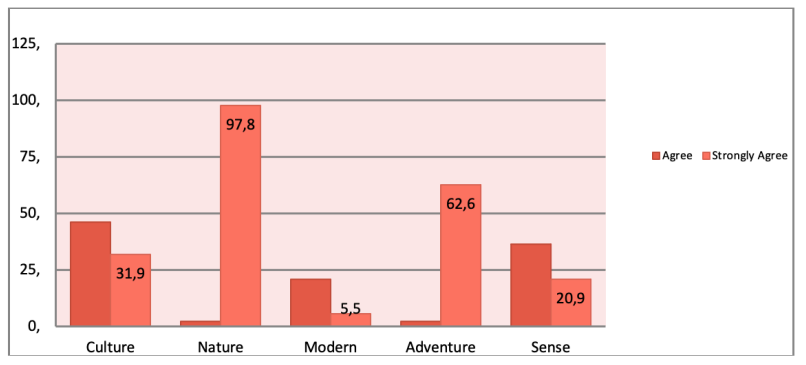

Gambar 3. Brand Image Wisatawan

\section{Analisis korelasi}

Untuk mengetahui pengaruh eWOM dalam hal ini online travel review terhadap brand knowledge wisatawan tentang Bali, dilakukan uji korelasi rank spearman. Data yang dikorelasikan adalah sumber informasi internet/sosial media dengan brand knowledge responden berdasarkan pengelompokan aktivitas wisata di Indonesia. Dari hasil analisis diperoleh hasil sebagaimana ditampilkan dalam Tabel 2 berikut ini.

Hasil analisis korelasi menunjukkan bahwa sumber informasi internet/sosial media dan brand knowledge wisatawan memiliki hubungan yang berbeda-beda atas lima pilihan wisata di Bali, dengan range koefisien korelasi yang diperoleh antara -.142 sampai .763.

Jika ditinjau dari kekuatan hubungan, eWOM dan wisata alam memiliki hubungan yang paling kuat, dibandingkan dengan aktivitas wisata adventur, kuliner dan kesehatan. Hasil yang cukup menarik diperoleh dimana eWOM dan wisata budaya memiliki hubungan yang sangat rendah. Sementara jika dilihat dari arah hubungan, pilihan aktivitas wisata budaya menunjukkan hubungan yang negatif dengan sumber informasi online. Sementara empat pilihan activitas lainnya yakni alam, modern, adventure dan senses memiliki hubungan yang positif dengan sumber informasi dalam online travel review platform.

Dari hasil tersebut dapat dikatakan bahwa dalam online travel review platform, hubungan eWOM dan brand knowledge tentang Bali sebagai destinasi wisata budaya rendah sekali dan berlawanan. Sebaliknya, hubungan antara eWOM dan Brand Knowledge tentang Bali sebagai destinasi wisata alam adalah kuat, siginifikan dan searah.

Hubungan yang kuat dan positif antara sumber informasi internet/sosial media dengan pilihan aktivitas wisata alam, berarti bahwa semakin tinggi/banyak informasi yang diperoleh melalui internet/sosial media maka akan meningkatkan brand knowledge wisatawan bahwa Bali merupakan destinasi wisata alam. Namun sebaliknya, hubungan yang rendah dan negatif menunjukkan bahwa sumber informasi melalui eWOM, tidak meningkatkan knowledge wisatawan bahwa Bali merupakan destinasi wisata budaya. Intepretasi output SPSS diperoleh koefisien korelasi $e W O M$ dan wisata budaya sebesar -0.142, maka diperoleh nilai $r^{2}$ (koefisien determinasi) sebesar 0.02 . Hal ini menunjukkan bahwa $e W O M$ berpengaruh sebesar 2\% terhadap brand knowledge wisatawan tentang Bali sebagai destinasi wisata budaya. Hasil tersebut berbanding dengan nilai koefisien determinasi untuk pengaruh eWOM terhadap brand knowledge wisatawan tentang wisata alam yang mencapai $58 \%$.

\section{PEMBAHASAN}

Internet merupakan lifestyle dan telah menjadi medium atau channel global dalam komunikasi pemasaran. Internet dan sosial media memungkinkan pengguna untuk saling berkomunikasi satu dengan lainnya, saling berbagi informasi dan opini yang mampu mempengaruhi calon pembeli dan memiliki kecenderungan untuk mengikuti trend dari lingkungan sosial mereka (Jalilvand, Esfahani \& Samiei, 2010).

Jika menelisik hasil analisis korelasi dalam penelitian ini, dimana brand knowledge wisatawan yang termediasi eWOM khususnya online travel review platform lebih besar pada Bali yang tergambarkan sebagai destinasi wisata alam, dibandingkan dengan Bali sebagai destinasi wisata budaya; maka hasil penelitian ini menunjukkan adanya gap antara wished image yang ingin ditampilkan oleh Pemerintah Provinsi Bali dengan perceived knowledge yang dimiliki oleh wisatawan. Di satu sisi, Pemerintah Provinsi Bali telah mencanangkan kepariwisataan barbasis budaya, sementara di sisi lain, berdasarkan informasi yang diperoleh melalui online travel review platform, wisatawan memiliki pengetahuan bahwa Bali memiliki alam sebagai keunggulan kompetitif.

Dalam era information highway saat ini, konsumen memiliki kuasa penuh (the most powerful) karena keputusan yang diambil berdasarkan pencarian informasi secara aktif tentang suatu brand. Trend ini sesuai teori pencarian informasi dimana dalam proses pengambilan keputusan, konsumen akan melakukan upaya pencarian informasi untuk menentukan pilihan produk/jasa yang akan dikonsumsi. Upaya ini dapat dilakukan secara internal (internal information search) dengan mengingat pengalaman masa lalu atau pengetahuan terkait pilihanpilihan tersebut. Jika pencarian internal ini belum mencukupi, konsumen akan melakukan pencarian tambahan (external information search), melalui beberapa cara, salah satunya melalui dari teman, sahabat atau rekan kerja (personal sources). Dengan memperhatikan hal tersebut di atas, maka dapat dikatakan bahwa wisatawan berusia muda ini secara terencana mencari informasi tentang topik tertentu (systematic information processing)

Proses ini terjadi dalam online travel review forum, seperti TripAdvisor. Upaya pencarian informasi external dilakukan dengan menggunggah pertanyaan berkaitan 
Tabel 2. Hasil Analisis Uji Korelasi Spearman. Untuk Brand Knowledge Wisatawan tentang Bali

\begin{tabular}{|c|c|c|c|c|c|c|c|}
\hline & & $\begin{array}{c}\text { Internet/ So- } \\
\text { cial Media }\end{array}$ & $\begin{array}{c}\text { Bali } \\
\text { Culture }\end{array}$ & $\begin{array}{c}\text { Bali } \\
\text { Nature }\end{array}$ & Bali Modern & $\begin{array}{l}\text { Bali Adven- } \\
\text { ture }\end{array}$ & $\begin{array}{c}\text { Bali } \\
\text { Culinary }\end{array}$ \\
\hline \multirow{3}{*}{$\begin{array}{l}\text { Internet/ So- } \\
\text { cial Media }\end{array}$} & $\begin{array}{l}\text { Pearson } \\
\text { Correlation }\end{array}$ & 1 & $-.142 *$ & $.763^{* *}$ & $.197 * *$ & $.450 * *$ & $.256^{* *}$ \\
\hline & $\begin{array}{l}\text { Sig. } \\
\text { (2-tailed) }\end{array}$ & & .019 & .000 & .001 & .000 & .000 \\
\hline & $\mathrm{N}$ & 273 & 273 & 273 & 273 & 273 & 273 \\
\hline
\end{tabular}

dengan rencana perjalanan dan/atau mencoba mencari jawaban atas pilihan yang ada berdasarkan pengalaman wisatawan yang sudah pernah mengalami sebelumnya. Bahkan tidak jarang, wisatawan yang menggunggah pertanyaan telah melakukan riset dengan membaca review tentang pilihan aktivitas dan area destiansi yang dituju, dan mencoba mengkonfirmasi hasil riset mereka dengan para destination expert dalam forum. Selain itu online travel forum juga dimanfaatkan untuk memberikan gambaran aktivitas wisata di Bali. Dalam online travel forum hal ini dikenal dengan istilah $H N R$ - here now report, yang mengacu pada upaya berbagi informasi dan pengalaman saat masih berada di Bali. Sementara, upaya berbagi informasi dan pengalaman yang dilakukan setelah melakukan perjalanan wisata, biasanya dilakukan saat setelah kembali ke negara asal, dalam online travel forum dikenal dengan istilah $J B R$ - just back report. Kedua jenis ini biasanya dilakukan dalam bentuk reportase perjalanan baik dalam bentuk tulisan maupun video perjalanan.

Konsumen sangat bergantung pada opini orang lain sehingga word-of-mouth menjadi rujukan penting dalam proses pengambilan keputusan (Kotler, Kartajaya, Setiawan, 2017). Hal ini akan menjadi tantangan tersendiri bagi suatu brand untuk mendapatkan perhatian konsumen (to win the customer attention). Salah satu upaya untuk mendapatkan perhatian konsumen adalah dengan membangun keterlibatan (engagement). Kepariwisataan Bali perlu membangun brand conversation pada online travel forum. Hal ini menjadi penting sebagai upaya untuk memastikan pada saat konsumen memerlukan informasi tentang Bali, akan ada loyal advocates yang dapat membantu konsumen mengambil keputusan untuk memilih Bali dan aktivitas wisata berbasis budaya.

Dimensi lain yang penting dalam komunikasi pemasaran adalah target audiens. Dari hasil penelitian diperoleh data bahwa wisatawan usia muda (youth traveller), yakni di bawah 35 tahun diikuti dengan usia 35 - 64 merupakan usia yang banyak memanfaatkan online travel review forum sebagai rujukan sebelum mengambil keputusan berwisata. Kelompok umur tersebut termasuk dalam generasi milenial, yang memiliki beberapa karakteristik menonjol yaitu pemanfatan internet dan sosial media sebagai sumber informasi dalam kehidupan sehari-hari (digital natives). Hal ini menjadikan generasi millennial berpeluang 2.5 kali lebih cepat mengadopsi informasi dan teknologi dibandingkan dengan generasi sebelumnya. Hal ini kemudian oleh Tinarbuko (2020) dinyatakan sebagai bagian dari pergerakan budaya visual, yang menjadikan internet sebagai kebutuhan multak.

Generasi ini memiliki kemampuan untuk memproduksi dan menggugah konten secara online, senang membaca review dan menelusuri informasi, termasuk membagi informasi tentang pilihan mereka secara online. Hal ini menyebabkan generasi milenial memiliki ketergantungan cukup tinggi pada rekomendasi dari sesama dan teman pengguna internet dan sosial media, dibandingkan dengan para ahli (expert) dan merasa senang jika keputusan yang mereka ambil mendapat persetujuan dari teman atau orang terdekat/peer affirmation (US Chamber of Commerce, 2012).

Selain faktor usia, trend motivasi wisatawan berkunjung saat ini lebih menekankan pada experience, dimana wisatawan ingin belajar dan berinteraksi langsung, tidak lagi hanya sekedar melihat, menonton atau menyaksikan suatu hal yang berkaitan dengan budaya setempat. Pengalaman dipandang memiliki sensasi yang lebih sehingga dapat membuat perjalanan wisata menjadi berkesan (Pine \& Gilmore, 2011; dalam Purnawan \& Sardiana, 2017). Oleh sebab itu, banyaknya informasi yang berkaitan dengan pilihan wisata alam dan adventure dalam online travel review akan berpengaruh terhadap brand knowledge wisatawan usia muda ini tentang Bali. "Escape, emotional recharge, authenticity, fulling experience, outdoor activities/adventures, and a general 
desire to participate and explore, rather than merely relax" (UNWTO, 2009).

Memperhatikan bahwa kategori wonderful nature, scenic landscape and wildlife sebagai aktivitas wisata favorit, muncul pertanyaan kemudian, apakah pilihan aktivitas wisata tersebut bersesuaian atau tidak dengan komitmen Pemerintah Provinsi Bali dalam mengembangkan kepariwisataan berbasis budaya?

Pariwisata budaya merupakan jenis perjalanan wisata tertua dan hingga saat ini tetap merupakan pasar pariwisata terbesar dan memiliki prospek untuk berkembang dengan pesat. Hal ini ditunjukkan dengan semakin banyaknya unsur budaya dan industri kreatif yang digunakan untuk mempromosikan dan meningkatkan advantages competitiveness dan attractiveness dari sebuah destinasi (Richard, 1996; OECD, 2014; Mousavi, 2016). Catatan OECD (2009; dalam Richards dan Munsters, 2010) menyebutkan sekitar $40 \%$ kepariwisataan internasional merupakan kegiatan wisata budaya. Pariwisata budaya adalah penggunaan potensi budaya dalam kegiatan pariwisata. Jika sebelumnya budaya identik dengan pendekatan 'sites dan monuments', perubahan ini kemudian memasukkan "everyday life" dalam ruang lingkup pariwisata budaya. Sehingga dapat dikatakan bahwa karakteristik pariwisata budaya berupa aktivitas pariwisata yang tidak saja menyangkut konsumsi dari produk budaya masa lalu - seperti mengunjungi tempat bersejarah atau museum saja, namun juga termasuk „mengkonsumsi "way of life"dari suatu masyarakat atau daerah yang dikunjungi. Kedua aktivitas budaya tersebut kemudian akan memberi peluang kepada pelancong untuk memperoleh pengetahuan dan pengalaman baru, yang mungkin berbeda dari kehidupan mereka sehari-hari. Selain itu, pariwisata budaya lebih menitikberatkan pada proses pembelajaran (learning aspect), dimana pelancong yang berminat menjalani pariwisata budaya termotivasi untuk mempelajari produk dan proses dari budaya lain yang berbeda dari budaya mereka sendiri. Seiring perkembangan, pariwisata juga mencakup menikmati suasana di suatu destinasi, mencoba kuliner lokal, selain mengunjungi museum atau konser klasik.

Sementara itu, yang dimaksud dengan Kepariwisataan Budaya Bali, sebagaimana tercantum dalam Perda Provinsi Bali No.2 Tahun 2012 adalah

"Kepariwisataan Bali yang berlandaskan kepada Kebudayaan Bali yang dijiwai oleh ajaran Agama Hindu dan falsafah Tri Hita Karana sebagai potensi utama dengan menggunakan kepariwisataan sebagai wahana aktualisasinya, sehingga terwujud hubungan timbal-balik yang dinamis antara kepariwisataan dan kebudayaan yang membuat keduanya berkembang secara sinergis, harmonis dan berkelanjutan untuk dapat memberikan kesejahteraan kepada masyarakat, kelestarian budaya dan lingkungan".
Komponen Budaya Bali yang menjadi potensi daya tarik wisata meliputi:1) kesenian; 2) kepurbakalaan; 3) kesejarahan; 4) permuseuman; 5) kesusastraan; 6) tradisi; dan 7) saujana.

Enam komponen awal merupakan produk dari proses budaya. Kata "saujana" mengandung arti "sejauh mata memandang". Selain tentang alam sekitar, kata "saujana" juga mengacu kepada interaksi antara manusia dengan budayanya dan alam (bentang lahan/lansekap) tempat mereka tinggal. Bentang alam memiliki nilai strategis dalam menentukan identitas suatu tempat, karena melalui bentang alamlah bisa diketahui awal mula keberadaan serta identitas suatu kelompok masyarakat. Landscape could play a significant role in determining the identity of the place. It is through landscape that one can understand about the origin, identity and about who we are (Shuib, Hashim, 2011; Mrda \& Bojana 2016).

Sehingga dapat dikatakan bahwa, kata "saujana" merupakan gabungan manusia, alam dan budaya dalam kesatuan ruang dan waktu, atau dikenal dengan istilah cultural landscape. Definisi cultural landscape sebagaimana dinyatakan oleh World Heritage Committee (1992) mencakup budaya yang menggambarkan adanya perpaduan antara alam dan manusia yang tinggal disekitarnya. Konsepsi ini mengandung makna bahwa landscape dapat didesain dan diciptakan dengan sengaja oleh manusia, atau terjadi secara alamiah atau assosiative cultural landscape karena adanya nilai religi, artistik atau asosiasi budaya terhadap unsur-unsur alam disekitarnya. Cultural landscape is the basic resource for the development of cultural tourism and that tourism always manifests itself in a space that contain certain natural and social attractiveness (Mrda, 2015).

Jika ditelusuri lebih dalam, keindahan dan kelestarian alam Bali yang menjadi driving role keputusan wisatawan datang ke Bali, tidak terlepas dari nilai yang dipegang teguh oleh masyarakat Bali, yang bernafaskan agama Hindu. Bagi masyarakat Bali, alam tidak bisa dipisahkan dari kehidupan manusia karena semua kehidupan ini berasal dari alam, yang diibaratkan sebagai "ibu pertiwi" (mother nature) yang harus dipelihara dan dijaga kelestariannya. Hal ini merupakan pula implementasi dari nilai agama Hindu adalah konsep Tri Hita Karana, yang mengajarkan kepada setiap individu untuk menjaga hubungan yang harmonis dengan Sang Pencipta, sesama manusia dan alam lingkungan sekitarnya. Nilai - nilai harmoni ini telah direcognisi oleh UNESCO sebagai nilai yang berlaku universal, salah satunya dengan ditetapkannya Subak sebagai warisan budaya dunia. "harmonious relationship between the realms of the spirit, the human world and nature (UNESCO, 2011).

Hobart (2019) menjabarkan lebih detail hubungan harmonis tersebut terjadi di Bali. Dinyatakan bahwa Bali ibaratnya seperti surga, suatu tempat layaknya museum 
hidup karena sangat kaya dengan budaya, perpaduan antara produk budaya, ritual, dan alam lingkungannya.

"Bali is an earthly paradise, a living cultural museum, a land of smiling people where almost everyone is an artist. They are heirs to a wonderfully rich tradition of music, dance, theatre, sculpture, painting and literature expressed in spectacular temple festivals and cremations, ... The landscape is breath-taking from looming volcanoes to the dramatic coastline. In between, surrounding ancient villages, lies a sea of green - an intricate mosaic of stunningly beautiful irrigated rice terraces" . Bali is fortune manifestation of wisdom which balance divinity, humanity and natural environment"

Dari pembahasan ini, dapat dikatakan bahwa, walaupun pilihan aktivitas wisata lebih banyak pada alam dan lingkungan sekitar, hal ini masih relevan dengan komitmen Pemerintah Provinsi Bali untuk mengembangkan kepariwisataan berbasis budaya.

\section{SIMPULAN}

Hasil penelitian ini menunjukkan bahwa internet dan media sosial telah berkembang menjadi salah satu sumber informasi utama dan pengaruh besar dalam proses pengambilan keputusan dan membentuk perilaku konsumen, terutama di kalangan wisatawan usia muda. Media sosial telah digunakan dalam setiap tahapan siklus berwisata, yakni sebelum, selama dan setelah melakukan perjalanan wisata. Hal ini disebabkan karena media sosial menyediakan platform, tidak saja untuk pencarian informasi tetapi juga untuk berinteraksi dan berbagi pengalaman antar konsumen. Hal ini menunjukkan bahwa eWOM khususnya online travel review merupakan medium pemasaran yang penting dan sangat berpengaruh bagi pembentukan brand knowledge wisatawan.

Banyaknya informasi tentang wisata alam dalam online travel review forum menunjukkan adanya berkorelasi positif dan kuat dengan pilihan brand knowledge wisatawan tentang wisata alam, namun sebaliknya informasi yang ada dalam online travel forum tersebut berkorelasi negatif dengan brand knowledge wisatawan tentang wisata budaya. Perbedaan persepsi batasan antara wisata alam dan wisata budaya di benak wisatawan dengan konsepsi kepariwisataan berbasis budaya menurut kepariwisataan Provinsi Bali berkontribusi terhadap hasil penelitian ini. Namun demikian, pilihan aktivitas wisata alam masih relevan dengan kepariwisataan berbasis budaya di Bali. Kata kunci atas relevansi ini adalah tercantumnya kata "saujana" yang mengacu pada interaksi dan keseimbangan antara manusia dan alam lingkungan sekitarnya sebagai salah satu komponen pariwisata budayayang dikembangkan di Bali (cultural landscape).
Rekomendasi yang dapat diberikan antara lain: 1) Bagi pemerintah/lembaga pemerintah yang berwenang terhadap pemasaran pariwisata Bali, pemanfaatan eWOM ini hendaknya mempertimbangkan penyiapan sumberdaya manusia (social media dedicated staff) yang memiliki pemahaman konsep budaya Bali dan komponen pariwisata budaya Bali, serta bertanggungjawab terhadap penyebaran informasi, termasuk keikutsertaan aktif sebagai sumber informasi dalam online travel forum; 2) Untuk memastikan penyebaran informasi dalam digital platform lebih terarah, pemerintah dan lembaga terkait bidang pemasaran hendaknya melakukan upaya-upaya menyamakan persepsi tentang komponen pariwisata budaya, baik kepada pihak internal ternasuk pemerintah, industri serta kepada masyarakat secara umum, sehingga semua pihak mampu memberikan informasi dan berperan sebagai ambassador kepariwisataan Bali yang berbasis budaya.

\section{DAFTAR RUJUKAN}

Anom, A., \& Revias Purwa Kusuma, M. (2019). Pengungkapan Estetika Fotografi "Instagramable” Di Era Pariwisata Destinasi Digital. Mudra Jurnal Seni Budaya, 34(3), 319-324. https://doi.org/10.31091/mudra.v34i3.787

Buhalis. D. (1998). Strategic Use of Information Technologies in the Tourism Industry, Tourism Management 19 (5)

(2000). Marketing: The Competitive Distinction of the Future, Tourism Management 21(1)

Buhalis, D. dan Law, R. (2008). Progress in Information Technology and Tourism Management : 20 Years On, 10 Years After the Internet - The State of eTourism Management. Tourism Management 29 (4)

Bungin, B., (2014). Komunikasi Pariwisata (Tourism Communication) : Pemasaran dan Brand Destinasi, Jakarta: Prenadamedia Group

Fill, C. (2005). Recent Development in Below-the-Line Marketing Communication. Dalam Kimmel, A.J.(Ed.) 2005. Marketing Communication : New Approaches, Technologies, and Styles. Oxford, London

Fill, C dan Turnbull, S. (2009). Marketing Communication: Touchpoints, sharing and disruption, Essex: Pearson

Hobart, M. (2019). How Bali Argue. Journal of Bali Studies, [S.1.], v. 9, n. 1, p. 1-34, apr. 2019. ISSN 25800698. Diunduh 2020 dari <https://ojs.unud.ac.id/index. php/kajianbali/article/view/48810> doi: https://doi. org/10.24843/JKB.2019.v09.i01.p01. 
Godes, D dan Mayzlin, D. (2004). 'Using Online Conversation to Study Word-of-Mouth Communication, Marketing Science Vol.23, No.4, Fall 2004

Gretzel, U., Kyung, H.Y, and Purifoy, M., (2007). Online Travel Review Study. Role and Impact of Online Travel Reviews. Texas: Laboratory for Intelligent Systems in Tourism, Texas A\& M University

Harrison-Walker, L.J. (2001). The Measurement of Word-of-Mouth Communication and Investigation of Service Quality and Customer Commitment as Potential Antecedents. .Journal of Service Research, Volume 4, No.1, August 2001 60-75

Hennig-Thurau, T., Gwinner, K.P., Walsh, G., Gremler, D.D., (2004). Electronic Word-of-Mouth via ConsumerOpinion Platform: What Motives Concumers to Articulate Themselves on the Internet. Journal of Interactive Marketing, Volume 18 Number 1 Winter 2004

Jalilvand, M.R., Esfahani, S.S., Samiei, N., (2010). Electronic word-of-mouth: Challenges and Opportunities. Procedia Computer Science 3 (2011) 42-46

Keller, K.L. (1993). Conceptualizing, Measuring and Managing Customer-Based Brand Equity. Journal of Marketing, Jan 1993; 57, 1

Kotler, P., Kartajaya, H, Setiawan, I. (2017). Marketing 4.0 - Moving from Traditional to Digital. New Jersey: John Wiley \& Sons Inc

Kotler, P. and Keller, K.L. (2012). Marketing Management, Boston: Prentice Hall

Kriyanto, R. (2006). Teknik Praktis Riset Komunikasi. Jakarta: Prenada Media Grup

Litvin, S.W., Goldsmith, R.E., Pan, B., (2006). Electronic Word-of-Mouth in Hospitality and Tourism Management. Tourism Management, Vol.29 Issue 3, June 2008, pp. 458468

Malik, F., (2016). Peranan Kebudayaan dalam Pencitraan Pariwisata Bali. Jurnal Kepariwisataan Indonesia, Vol.11 No.1 Juni 2016

Minazi, R. (2015). Social Media Marketing in Tourism and Hospitality. Springer International Publishing, Switzerland

Mousavi, S.S., Doratli, N., Mousavi, S.N., Moradiahari, F. (2016). "Defining Cultural Tourism'. International Conference on Civil, Architecture, and Sustainable Development (CASD-2016) Dec 1-2, 2016, London (UK)
Mrda, A dan Bojana, B.O.S. 2016. Heritage Touristscapes: A Case Study of The Islands of Hvar'. ANNALES, Series Historia et Sociologia, 26, 2016, 3

Munar, A.M. (2012) 'Social Media Strategies and Destination Management', Scandinavian Journal of Hospitality and Tourism Vol.12, No.2, 101-120, 2012, [online] \{diakses 20 April 2015\}

Morrison, A.M. (1996). Hospitality and Travel Marketing, New York: Delmar Publisher

Picard, M. (1995). 'Cultural Heritage and Tourist Capital: Cultural Tourism in Bali' dalam Lanfant, M.F., Allcock, J.B., dan Bruner, E.M. (Eds) International Tourism, Identity and Change. (1995). SAGE: London, pp. 44-66

Pemerintah Daerah Provinsi Bali. (2012). Rencana Induk Pengembangan Pariwisata Daerah Bali, Denpasar

Purnawan, N. L.R., Pitana, I G., Darma Putra, I N., (2019). "How Bali is Portrayed in Online Review Communication: Software-Assisted Content Analysis Approach", Journal of Tourism and Hospitality Management Vol.7, No.2, December 2019.

Purnawan, N.L.R dan Sardiana, I K, (2017). "Paket Wisata Edukasi Subak Upaya Menjaga Keberlanjutan Potensi Pertanian dan Pariwisata Berbasis Budaya di Bali", Kawistara: Jurnal Ilmiah Sosial dan Humaniora, Vol.7 No.3, 22 Desember 2017, 238-248

Richards, G. Dan Munsters, W. (2010). "Development and Perspectives in Cultural Tourism Research" dalam Richard, G dan Munster, W (Eds), 2010. Cultural Tourism Research Methods. CABI, Oxford

Richards, G (Ed) (1996). Cultural Tourism in Europe. CAB International, Wallingford, UK

(2009). Tourism Development Trajectories from Culture to Creativity. The Asia-Pacific Creativity Forum on Culture and Tourism, Korea 3-5 Juni 2009

Swandi, I. W. (2017). Dampak Sosial Pariwisata Di Bali Dalam Kartun Bog-bog edisi 2011/2012. Mudra Jurnal Seni Budaya, 32(2). https://doi.org/10.31091/mudra v32i2.109

Tinarbuko, S. (2020). Makna Konotasi Rebranding Logo TVRI. Mudra Jurnal Seni Budaya, 35(1), 15-21. https:// doi.org/10.31091/mudra.v35i1.993 
UNWTO. (2009). Handbook on Tourism Destination Branding. UNWTO and European Travel Commission, Madrid

(2016). UNWTO Recommendations on Accessible Information in Tourism, UNWTO, Madrid.

U.S. Chamber of Commerce. (2012). The Millennial Generation. Research Review. US Chamber of Commerce, Washington DC

Xiang, Z dan Gretzel, U. (2010). Role of Social Media in Online Travel Information Search. Tourism Management 31 (2010) 179-188, [online] \{diakses 5 Mei 2015\}

Zhang, Y. (2015). "The Impact of Brand Image on Consumer Behavior : A Literature Review, Open Journal of Business and Management, 2015, 3, pp. 58-62

Zhu, F \& Zhang X. (2010) "Impact of Online Consumer Reviews on Sales: The Moderating Role of Product and Consumer Characteristic" Journal of Marketing Vol. 74 (March 2010), 133-148

www.indonesia.travel www.tripadvisor.com www.hootsuite.com www.worldstatistic.com 